\title{
Neurodevelopmental and epilepsy outcomes of patients with infantile spasms treated in a tertiary care center
}

\author{
Fahad A. Bashiri, MD, Matar A. Al-Sehemi, MD, Muddathir H. Hamad, MD, Nawaf R. Alshammari, MD, Mujtaba A \\ Aljumah, MD, Amal Kentab, MD, Mustafa A. Salih, MD.
}

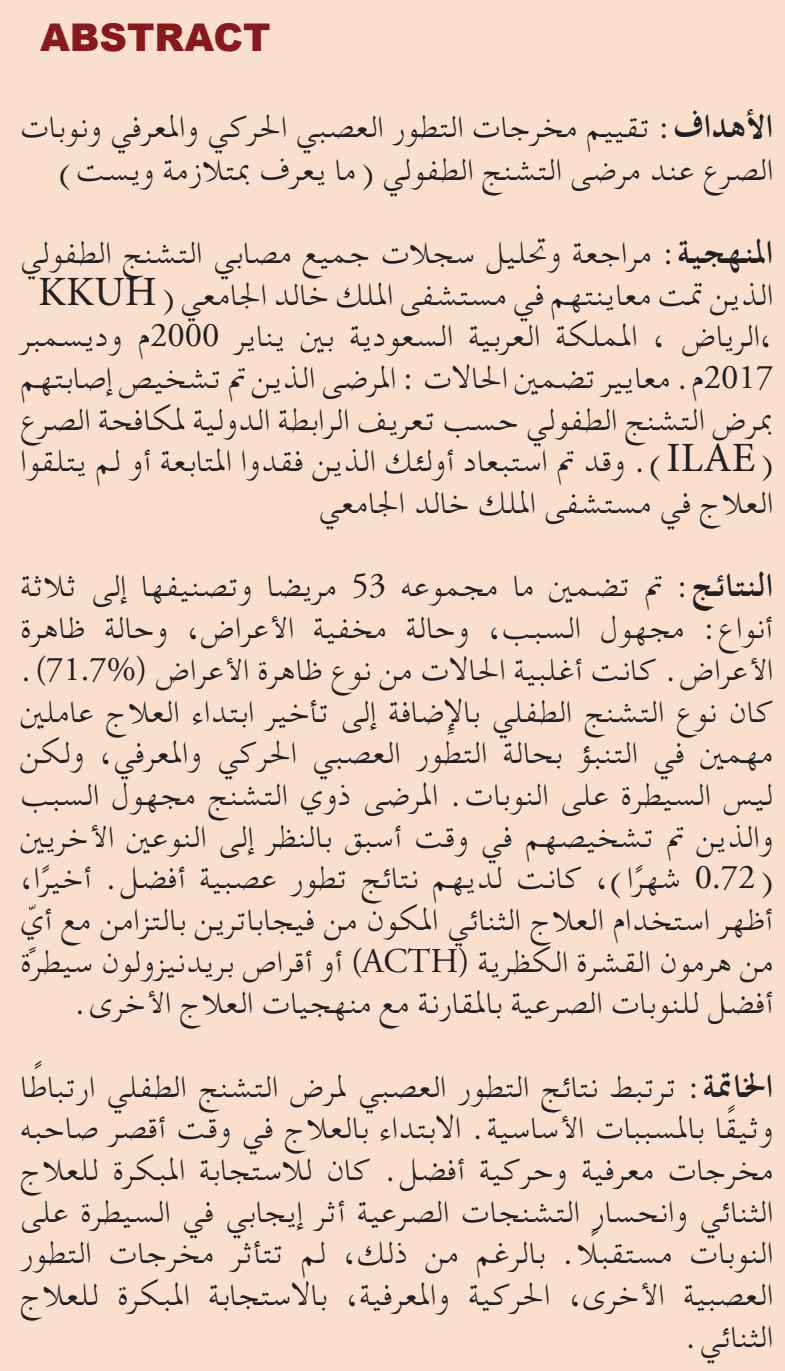

Objectives: To assess the neurodevelopmental and epilepsy outcomes in children with infantile spasms (IS).

Methods: A retrospective chart review of all patients with infantile spasms admitted to King Khalid University Hospital (KKUH), Riyadh, Saudi Arabia between January 2000 and December 2017. Infants who were diagnosed to have IS as per the International
League Against Epilepsy (ILAE) definition were included in this study. Patients who lost follow-up and those who did not receive treatment at KKUH were excluded.

Results: Total of 53 patients were included and categorized into unknown, cryptogenic and symptomatic type of IS. The majority had symptomatic etiology (71.7\%). Type of etiology and delay in initiation of treatment were significant predictors of motor and cognitive outcomes, but not seizure control. Patients with unknown IS, who were diagnosed earlier (0.72-month), had better neurodevelopmental outcomes. Vigabatrin in combination with either Adrenocorticotropic hormone $(\mathrm{ACTH})$ or Prednisolone showed better seizure control in comparison to monotherapy and other combination modalities.

Conclusion: Neurodevelopmental outcomes of IS are strongly associated with the underlying etiology. Early initiation of treatments had a favorable cognitive and motor outcome. Early response to combination therapy with resolution of spasms and hypsarrhythmia had better seizure outcomes. However, motor and cognitive outcomes were not affected by the response to the combination therapy.

Neurosciences 2021; Vol. 26 (1): 21-25 doi: 10.17712/nsj.2021.1.20200087

From the Division of Pediatric Neurology (Bashiri, Al-Sehemi, Hamad, Aljumah, Kentab, Salih), Department of Pediatrics (Alshammari), College of Medicine, King Saud University, Riyadh, Kingdom of Saudi Arabia

Received 31st May 2020. Accepted 11th August 2020.

Address correspondence and reprint request to: Dr. Fahad $A$. Bashiri, Division of Pediatric Neurology, Department of Pediatrics, College of Medicine, King Saud University, Riyadh, Kingdom of Saudi Arabia.E-mail: fbashiri@ksu.edu.sa

ORCID ID: https://orcid.org/0000-0003-1436-6727

Disclosure. Authors have no conflict of interests, and the work was not supported or funded by any drug company. 
$\mathrm{I}$ nfantile spasms (IS) is a rare form of epileptic encephalopathy characterized by spasms and hypsarrhythmia on the electroencephalogram (EEG). ${ }^{1}$ IS is diagnosed at 6 months of age on average. ${ }^{2}$ There are no reports on the incidence of IS in Saudi Arabia. International estimates put the figure at 1:6,000 1:4,000 live births. Studies suggest that IS constitutes $2 \%$ of childhood epilepsies, and a quarter of epilepsy cases are seen during the first year of life. ${ }^{3}$ The etiology of IS is divided into prenatal, perinatal, or postnatal disorders. ${ }^{3}$ Genetic defects associated with IS are increasingly being understood. Tuberous sclerosis is the most common disorder associated with IS and constitutes $10-30 \%$ of symptomatic IS. It is an autosomal dominant disorder caused by mutations in TSC1 and TSC 2 genes, with variable manifestations, including cardiac and renal tumors, cutaneous malformations, and seizures. ${ }^{4}$ Mutations in the ARX gene and cyclin-dependent kinase-like protein 5 (CDKL5), 14q12 duplications harboring FOXG1, STXBP1, and PLCB1 have been also implicated in IS..$^{5-8}$ Other prenatal causes include hydrocephalus, hydranencephaly, Trisomy 21, Hypoxicischemic encephalopathy, congenital infections, and trauma. IS can also occur secondary to a perinatal or postnatal disorders, including meningitis, trauma, encephalitis, intracranial hemorrhage, and inborn errors of metabolism. ${ }^{?}$

When there is no clear cause of IS identified, IS can be labeled as unknown or cryptogenic. Uunknown IS is characterized by normal development prior to the onset of IS. Cryptogenic IS, on the other hand, is diagnosed when no known etiology is determined, but prior developmental delay has occurred. ${ }^{10}$

Neurodevelopmental regression is characteristic of IS, and children with history of IS often have poor neurodevelopmental outcomes. ${ }^{11}$ In a cohort of 180 patient, $53 \%$ of infants with symptomatic IS have normal seizure status and cognitive development compared to $21.9 \%$ of infants with unknown IS. ${ }^{12}$

The long-term survival of patients with IS thought to be poor and was related to the underlying condition, where unknown IS generally has a better prognosis than symptomatic IS. ${ }^{11}$ The aim of this study was to identify those patients and treatment factors that correlate with favorable neurodevelopmental and epilepsy outcomes in a tertiary hospital in Saudi Arabia.

Methods. A retrospective chart review of children with IS who were admitted to King Khalid University Hospital (KKUH) between January 2000 and December 2017 were obtained after the approval of the institutional review board (IRB). Infants below 2 years of age who had IS, based on the International League Against Epilepsy (ILAE) definition, and who were followed up for at least one year were included in the study. Infants with a history of an underlying condition that causes epilepsy not characteristic of IS or not receiving treatment in our hospital were excluded. Details of clinical characteristics, lab investigations, antiseizure medications (ASMs) and treatment outcome were collected and analyzed. The onset of disease was defined from the time parents first note spasms or developmental regression. Response to treatment, or seizure control, was defined as clinical resolution of spasms and hypsarrhythmia for at least one month. The physical therapy evaluation of fine and gross motor skills was used to report the motor developmental outcome.

Table 2 - Etiological Categorization.

\begin{tabular}{lcc}
\hline Etiology & $\mathbf{n}$ & $(\%)$ \\
\hline Unknown & 8 & $(15.1)$ \\
Cryptogenic & 7 & $(13.2)$ \\
Symptomatic & 38 & $(71.7)$ \\
Perinatal asphyxia & 9 & $(17)$ \\
CNS malformation & 10 & $(18.9)$ \\
Tuberous sclerosis & 5 & $(9.4)$ \\
Metabolic & 3 & $(5.7)$ \\
Chromosomal anomaly & 5 & $(9.4)$ \\
Hypomelanosis of Ito & 2 & $(3.8)$ \\
Other & 4 & $(7.5)$ \\
Total & 53 & $(\mathbf{1 0 0 . 0 )}$ \\
\hline
\end{tabular}

Table 1 - Demographic Characteristics.

\begin{tabular}{lcccc}
\hline Etiology & Unknown & Cryptogenic & Symptomatic & Total \\
\hline Gender & & & & \\
Male & $4(7.5)$ & $2(3.7)$ & $18(34)$ & $24(45.2)$ \\
Female & $4(7.5)$ & $5(9.5)$ & $20(37.8)$ & $29(54.8)$ \\
Age at onset of spasms (months) & 7.8 & 8.0 & 7.4 & 7.8 \\
Age at start of treatment (months) & 8.5 & 9.6 & 8.8 & 9.0 \\
Delay in treatment (months) & 0.72 & 1.6 & 1.4 & 1.3 \\
\hline
\end{tabular}


Table 3 - Neurodevelopmental outcomes.

\begin{tabular}{|c|c|c|c|c|c|c|c|c|c|}
\hline \multirow[t]{2}{*}{ Measurement } & \multicolumn{3}{|c|}{ Epilepsy } & \multicolumn{3}{|c|}{ Motor } & \multicolumn{3}{|c|}{ Cognitive } \\
\hline & $\begin{array}{c}\text { Good } \\
\text { outcome }\end{array}$ & $\begin{array}{c}\text { Poor } \\
\text { outcome }\end{array}$ & $P$-value & $\begin{array}{c}\text { Good } \\
\text { outcome }\end{array}$ & $\begin{array}{c}\text { Poor } \\
\text { outcome }\end{array}$ & $P$-value & $\begin{array}{c}\text { Good } \\
\text { outcome }\end{array}$ & $\begin{array}{c}\text { Poor } \\
\text { outcome }\end{array}$ & $P$-value \\
\hline Etiology & & & 0.314 & & & $0.003^{*}$ & & & $0.001^{*}$ \\
\hline Unknown & $7(13.2)$ & $1(1.9)$ & & $7(13.2)$ & $1(1.9)$ & & $7(13.2)$ & $1(1.9)$ & \\
\hline Cryptogenic & $4(7.5)$ & $3(5.7)$ & & $2(3.8)$ & $5(9.4)$ & & $1(1.9)$ & $6(11.3)$ & \\
\hline Symptomatic & $24(45.3)$ & $14(26.4)$ & & $9(17)$ & $29(54.7)$ & & $7(13.2)$ & $31(58.5)$ & \\
\hline Gender & & & 0.502 & & & 0.502 & & & 0.272 \\
\hline Male & $17(70.8)$ & $7(29.2)$ & & $7(70.8)$ & $17(29.2)$ & & $5(20.8)$ & $19(79.2)$ & \\
\hline Female & $18(62.0)$ & $11(38.0)$ & & $11(38.0)$ & $18(62.0)$ & & $10(34.5)$ & $19(65.5)$ & \\
\hline Age at onset of spasms (months) & 6.30 & 10.20 & 0.138 & 7.39 & 7.63 & 0.898 & 6.87 & 7.82 & 0.628 \\
\hline Delay in treatment (months) & 0.82 & 1.64 & 0.116 & 0.44 & 1.41 & $0.010^{*}$ & 0.40 & 1.36 & $0.006^{*}$ \\
\hline \multicolumn{10}{|c|}{${ }^{*}$ Statistically significant } \\
\hline
\end{tabular}

Table 4 - Initial treatment.

\begin{tabular}{lcc}
\hline Initial therapy & $\mathbf{n}$ & $(\%)$ \\
\hline ACTH/Prednisolone & 6 & $(11.32)$ \\
Vigabatrin & 18 & $(33.96)$ \\
Combination therapy & 20 & $(37.73)$ \\
ACTH/Prednisolone/Vigabatrin + Other & 9 & $(16.98)$ \\
\hline
\end{tabular}

Cognitive development was assessed through speech and language skills in addition to IQ test and school performance reported by parents when applicable. The patients were dispensed and labeled as normal or impaired for each developmental aspect: seizure control, motor and cognitive development.

Statistical analysis. Descriptive statistics, student's t-test, z-proportional test and chi-squared tests were employed to compare group variables between gender and demographic variables using IBM SPSS Statistics for Windows, version 21 (IBM Corp., Armonk, N.Y., USA). For all tests, statistical significance set at $p<0.05$.

Results. Patient characteristics. Total of 53 patients with IS treated at our institution were involved in the study. There were no differences in the gender distribution, age at onset of spasms, or age at start of treatment between the unknown, cryptogenic and the symptomatic patient populations. Most of the patients had a symptomatic etiology $71.7 \%$, with only about $13.2 \%$ had cryptogenic type and $15.1 \%$ unknown IS. Children with unknown IS had early treatment (0.72 months) compared to both cryptogenic (1.6 months) and symptomatic (1.4 months). Demographic Characteristics was shown in Table 1 . The most common symptomatic etiologies were structural brain malformation (18.9\%), perinatal asphyxia (17\%), chromosomal anomaly (9.4\%), and Tuberous Sclerosis $(9.4 \%)$. Four patients were designated as having a symptomatic etiology due to nonspecific magnetic resonance imaging (MRI) findings demonstrating abnormal myelination pattern or due to developmental delay clearly preceding the onset of spasms. Table 2 showed etiological categorization.

Type of etiology of IS was significantly correlated with motor $(p=0.003)$ and cognitive outcomes $(p=0.001)$, but not with seizure control. Abnormal motor developmental outcome in symptomatic IS was (82.9\%) while unknown IS only (2.9\%) and cryptogenic (14.2\%). Cognitive impairment of unknown etiology was (2.6\%), cryptogenic (15.8\%), and symptomatic IS $(81.6 \%)$. Gender was not predictive of developmental outcomes. Age at onset of spasms was also not significantly associated with any outcome. On the other hand, delay in initiation of treatment of IS for 1.41 -month was affecting motor outcome negatively $(p=0.01)$. Likewise, patients whom had 1.36-month delay treatment showed worse cognitive consequences in relation to whom had a delay of less than 2-week period ( $p=0.006)$. Neurodevelopmental Outcomes was shown in Table 3. Hormonal therapy alone, high ACTH or prednisolone, were administered as initial therapy in $(11.32 \%)$ of the patients, while Vigabatrin alone used in (34\%). Combining corticosteroids and vigabatrin was the initial therapy in (38\%). Patients started on other ASMs, such as topiramate and valproic acid, in addition to the recommended first-line therapy were only (17\%). Ketogenic diet was not given to any patient. Table 4 showed initial treatment used. None of the treatment modalities mentioned above showed statistical significance for good developmental outcome, higher response rate was associated with ACTH/ prednisolone in combination with vigabatrin (33.3\%). The group of patients who responded to combination 
Table 5 - Response to treatment and outcome.

\begin{tabular}{lccc}
\hline Response to treatment & Good Epilepsy Outcome & Good Motor Outcome & Good Cognitive Outcome \\
\hline ACTH/Prednisolone & $4(8.3)$ & $1(2.1)$ & $0(0)$ \\
Vigabatrin & $13(20.8)$ & $9(10.4)$ & $5(8.3)$ \\
Combination therapy & $16(33.3)$ & $9(18.8)$ & $7(14.6)$ \\
ACTH/Prednisolone/Vigabatrin + Other & $3(4.2)$ & $1(2.1)$ & $2(2.1)$ \\
\hline
\end{tabular}

therapy had resolution of spasms and hypsarrhythmia with better seizure outcomes. However, motor and cognitive outcomes were not affected by the response rate to the combination therapy Table 5 showed response to treatment and outcome.

Discussion. In this study, we aimed to assess the etiology, the neurodevelopmental outcomes, and the treatments of patients with IS. The etiology of IS was classified into three categories depending on the developmental maturation at the time when IS was diagnosed, and whether an overt cause was identified. Most patients $(71.7 \%)$ in this study had symptomatic IS. This is in line with the common etiology of IS in other populations. ${ }^{13}$ While we cannot rule out the effect of medical and socioeconomical factors, we believe that patients in this study represent typical presentation patterns of patients with IS. ${ }^{14}$ Additionally, it appears that IS presents at a mean age of 7.8 months, which is older than found in the literature, ${ }^{15}$ which can be attributed to decrease knowledge and lack of recognition of the spasms from parents.

In consistence with North American Cohort study, ${ }^{16}$ our results demonstrated a predictive value of the etiology type to the motor and cognitive outcomes. Idiopathic or Unknown etiology of IS were much more likely to have a better motor and cognitive outcome than those with symptomatic IS. Seizure control has no association with the etiology of IS. As our result have demonstrated, the unknown group of IS had started the treatment earlier, average of 0.72 month, compared to cryptogenic (1.6 month) and symptomatic (1.4 month). This difference in initiation of treatment may have an impact on the outcome.

Guidelines are not uniform with regards to treatment initiation. While some studies suggested that good neurodevelopmental outcomes are associated with early treatment initiation, a delay of one and half month period was significantly critical in predicting unpleasant motor and cognitive outcomes in our study. ${ }^{17} \mathrm{~A}$ systematic review by Widjaja et $\mathrm{al}^{18}$ found that a lead time to treatment of duration less than 4 weeks is associated with better neurodevelopmental outcomes.

We found that seizure control with combination therapy of vigabatrin and corticosteroids was associated with favorable neurodevelopmental outcomes in our patients although studies indicated that response to monotherapy versus combination therapy might be associated with improved long-term neurodevelopmental outcomes. ${ }^{19}$ A randomized controlled trial showed that combination therapy did not improve developmental or epilepsy outcomes at 18 months. ${ }^{20}$ A possible explanation of the high response rate to combination therapy in our study is the relatively long lead time, average of 1.3 month.

The Guideline Development Subcommittee of the American Academy of Neurology and the Practice Committee of the Child Neurology Society has reported that adrenocorticotrophic hormone (ACTH) are more effective than Vigabatrin, except in cases where TS has been diagnosed. There is no established evidence whether corticosteroids other than $(\mathrm{ACTH})$ are as effective as ACTH as short-term therapy in children with IS. However, low-dose ACTH might be as effective as high-dose ACTH. More importantly, a short duration between onset of IS and initiation of treatment is associated with better long-term developmental outcome. ${ }^{17,20}$ Short-term treatment of IS with ACTH or prednisolone is associated with improved seizure control compared to treatment with Vigabatrin. ${ }^{21}$ Selecting an ideal treatment modality is of challenge due to the wide range of etiologies. ${ }^{22}$ However, we did not find an association between type of initial treatment and etiology, given a limited number of patients who were started on ACTH.

Limitations of the study. The retrospective nature of the study. Treatment delay should ideally be assessed prospectively and must include time until resolution of spasms and hypsarrhythmia in EEG. A small sample size is another limitation. Treatment protocols must also be studied in terms of short-term efficacy and long-term impact on seizure control and neurodevelopmental outcomes. Further studies on the effective of initiating a 
combination therapy on long-term neurodevelopmental outcome, with respect to the lead time, is recommended. Lastly, long-term follow-up of patients with intractable epilepsy, including Lennox- Gastaut syndrome, may carry out mechanisms of early brain injury that predict the outcome.

In conclusion, neurodevelopmental outcomes of IS are strongly associated with the underlying etiology. Delay in initiation of treatment may result in worse motor and cognitive impairment. Combination therapy is associated with better resolution of spasms and hypsarrhythmia than other modalities. However, motor and cognitive outcomes were not affected by response to combination therapy.

Acknowledgment. $\quad M . \quad A . \quad S$. was supported by Researchers Supporting Project (RSP2020138), King Saud University, Riyadh, Saudi Arabia.

\section{References}

1. Hrachovy RA, Frost JD, Jr. Infantile spasms. Handb Clin Neurol 2013; 111: 611-618.

2. Paciorkowski AR, Thio LL, Dobyns WB. A genetic and biologic classification of infantile spasms. Pediatr Neurol 2011; 45: 355-367.

3. Wilmshurst JM, Ibekwe RC, O'Callaghan FJK. Epileptic spasms - 175 years on: Trying to teach an old dog new tricks. Seizure 2017; 44: 81-86.

4. Saxena A, Sampson JR. Epilepsy in Tuberous Sclerosis: Phenotypes, Mechanisms, and Treatments. Semin Neurol 2015; 35: 269-276.

5. Galanopoulou AS, Moshe SL. Neonatal and Infantile Epilepsy: Acquired and Genetic Models. Cold Spring Harb Perspect Med 2015; 6: a022707.

6. Striano P, Paravidino R, Sicca F, Chiurazzi P, Gimelli S, Coppola A et al. West syndrome associated with $14 \mathrm{q} 12$ duplications harboring FOXG1. Neurology 2011; 76: 1600-1602.

7. Mignot C, Moutard M, Trouillard O, Gourfinkel-An I, Jacquette A, Arveiler B, et al. STXBP1-related encephalopathy presenting as infantile spasms and generalized tremor in three patients. Epilepsia 2011; 52: 1820-1827.

8. Myers K. PLCB1 Biallelic Point Mutations Cause West Syndrome. Pediatric Neurology 2019; 91: 62-64.

9. Taghdiri MM, Nemati H. Infantile spasm: a review article. Iran J Child Neurol 2014; 8: 1-5.

10. Lux AL, Osborne JP. A proposal for case definitions and outcome measures in studies of infantile spasms and West syndrome: consensus statement of the West Delphi group.
Epilepsia 2004; 45: 1416-1428.

11. Metsahonkala L, Gaily E, Valanne L, Blomstedt G. Etiology and Long-Term Outcomes of Late-Onset Infantile Spasms. Neuropediatrics 2015; 46: 269-276.

12. Djuric M, Kravljanac R, Tadic B, Mrlješ-Popovic N, Appleton RE. Long-term outcome in children with infantile spasms treated with vigabatrin: A cohort of 180 patients. Epilepsia 2014; 55: 1918-1925.

13. Mikati MA, Lepejian GA, Holmes GL. Medical treatment of patients with infantile spasms. Clin Neuropharmacol 2002; 25 : 61-70.

14. Wilmshurst JM, Gaillard WD, Vinayan KP, Tsuchida TN, Plouin P, Van Bogaert P, et al. Summary of recommendations for the management of infantile seizures: Task Force Report for the ILAE Commission of Pediatrics. Epilepsia 2015; 56 : 1185-1197.

15. Pellock J, Hrachovy R, Shinnar S, Baram T, Bettis D, Dlugos $\mathrm{D}$ et al. Infantile spasms: A U.S. consensus report. Epilepsia 2010; 51: 2175-2189.

16. Partikian A, Mitchell W. Neurodevelopmental and Epilepsy Outcomes in a North American Cohort of Patients With Infantile Spasms. J Child Neurol 2010; 25(4): 423-428.

17. Go CY, Mackay MT, Weiss SK, Stephens D, Adams-Webber T, Ashwal S, et al. Evidence-based guideline update: medical treatment of infantile spasms. Report of the Guideline Development Subcommittee of the American Academy of Neurology and the Practice Committee of the Child Neurology Society. Neurology 2012; 78: 1974-1980.

18. Widjaja E, Go C, McCoy B, Snead OC. Neurodevelopmental outcome of infantile spasms: A systematic review and metaanalysis. Epilepsy Res. 2015; 109: 155-162.

19. Lombroso CT. A prospective study of infantile spasms: clinical and therapeutic correlations. Epilepsia 1983; 24: 135-158.

20. O'Callaghan FJK, Edwards SW, Alber FD, Borja MC, Hancock E, Johnson AL, et al. Vigabatrin with hormonal treatment versus hormonal treatment alone (ICISS) for infantile spasms: 18-month outcomes of an open-label, randomised controlled trial. Lancet Child Adolesc Health 2018; 2: 715-725.

21. O'Callaghan FJK, Edwards SW, Alber FD, Hancock E, Johnson AL, Kennedy CR, et al. Safety and effectiveness of hormonal treatment versus hormonal treatment with vigabatrin for infantile spasms (ICISS): a randomised, multicentre, open-label trial. Lancet Neurol 2017; 16: 33-42.

22. Specchio N, Pietrafusa N, Ferretti A, De Palma L, Santarone ME, Pepi C, et al. Treatment of infantile spasms: why do we know so little? Expert Rev Neurother 2020; 20: 551-566. 